\title{
ISOLATION AND IDENTIFICATION OF PHYTOCHEMICAL CONSTITUENTS FROM THE ROOTS OF Calliandra portoricensis
}

\author{
Nvau, J. B.**a Saidu, S. B. ${ }^{a}$, Okonkwo, F. O. ${ }^{b}$, Gray, A. I. ${ }^{c}$ Igoli, J. O. ${ }^{c, d}$ \\ ${ }^{a}$ Department of Chemistry, Plateau State University, Bokkos, PMB 2012, Jos. Nigeria. \\ ${ }^{b}$ Department of Biochemistry, Plateau State University, Bokkos, PMB 2012, Jos. Niger \\ 'Strathclyde Institute of Pharmacy and Biomedical Sciences, University of Strathclyde, 161 Cathedral Street, G4 0RE, \\ Glasgow UK. \\ ${ }^{\mathrm{d}}$ Department of Chemistry, University of Agriculture, PMB 2373 Makurdi, Nigeria. \\ *Corresponding Author: E-mail; johnnvau@yahoo.com Phone +234 8035807728
}

(Received: $5^{\text {th }}$ March, 2020; Accepted: $24^{\text {th }}$ May, 2020)

\section{ABSTRACT}

\begin{abstract}
Calliandra portoricensis is a plant widely used in Nigerian ethnomedicine for the treatment of tuberculosis and other respiratory conditions. In view of its traditional use, the present study is aimed at the isolation and identification of bioactive components or secondary metabolites which may be responsible for its biological activity. The air dried roots was extracted with hexane, ethyl acetate and then methanol via maceration at room temperature. Repeated column chromatography of the ethyl acetate extract over silica gel yielded linalonic acid, spinasterone, lupeol, daucosterol and triacontanyl caffeate. The structures of these compounds were determined by NMR, mass spectrometry and comparison with literature. This is an initial report of these compounds from the plant material.
\end{abstract}

Key words: Linalonic acid, Triacontanyl caffeate, Daucosterol, Spinasterone, Nigeria

\section{INTRODUCTION}

Calliandra portoricensis (Jacq) Benth belongs to the family Mimosaceae. It is a straggling perennial shrub found mostly in West Indies, Panama and Mexico. (Hutchinson, 1937). It is also found in many tropical countries such as Cote de Voire and Nigeria. The plant has a long standing use in Nigerian traditional medicine (Akah and Nwaiwu, 1985, Enwuru et al., 2017). The plant is used by traditional herbal medicine practitioners for the treatment of lumbago, constipation, gonorrhea as a laxative and worm expeller, and convulsion (Adesida, 1976; Akah and Nwaiwu, 1988). Also reported is its anticonvulsant, analgesic, antidiarrheal, antispasmodic and antipyretic activities (Abdulkarim et al., 2005) and its extracts have shown anticholigenic, antacid, antiulcer, molluscidal and ovicidal activities in laboratory animals (Aguwal et al., 1988). Antimicrobacterial activities of the plants have been reported against Escherichia coli., Staphylococcus aureus, Streptococcus faecuim and Candida albicans (Adesina, 1982 and Abdulkarim et al., 2005). Phytochemical constituents such as tannins, saponins, flavonoids, cardiac glycosides have been reported to be present in the extracts of the plant (Aguwal et al., 1988; Lawal et al., 1998.; Orishadipe et al., 2004 and Falode et al., 2018). However, the phytochemical constituents of these active extracts were not isolated or identified. In this study we report for the first time the isolation of five compounds from the roots of Calliandra portoricensis and their spectroscopic identification.

\section{MATERIALS AND METHODS \\ General}

The ${ }^{1} \mathrm{H}$ and ${ }^{13} \mathrm{CNMR}(400 \mathrm{MHz})$ spectra were obtained on a Bruker DPX 400 spectrophotometer using $\mathrm{CDCl}_{3}$ as solvent and TMS as internal standard. Barnstead Electrothermal 9100 melting point apparatus was used to determine melting points, without corrections. TLC was performed on silica gel $\mathrm{F}_{254}$ $(0.25 \mathrm{~mm})$ precoated plates and column chromatographic were carried out in glass columns using silica gel (120-230 mesh, GmbH \& Co. KG). Solvents were purchased from commercial sources and redistilled before use. Spots on tlc were visualized with $10 \%$ sulfuric acid in ethanol, followed by heating.

\section{Plant Material}

The roots of Calliandraportoricensis were purchased from a traditional healer in Jos, Plateau State, Nigeria and certified at the School of Forestry Jos. The roots were dried at room temperature for two 
weeks and thereafter ground into powder and used for extraction.

\section{Extraction and Isolation}

The powdered roots $500 \mathrm{~g}$ was extracted with hexane, ethyl acetate and then methanol for 48 hours each. The solvents were recovered using a rotary evaporator at reduced temperature and pressure. $5.0 \mathrm{~g}$ of the ethyl acetate extract was dissolved in ethyl acetate and adsorbed on to $15 \mathrm{~g}$ of silica gel, and allowed to dry at room temperature. A column was packed with $120 \mathrm{~g}$ of silica gel in hexane. The adsorbed extract was loaded unto the packed column. The column was eluted with hexane and then with increasing quantities of ethyl acetate in hexane and collecting $100 \mathrm{ml}$ fractions. A total of 180 fractions were collected. All the fractions were examined by tlc and similar fractions were combined to obtain eleven pooled fractions F1 - F11. Fractions F3 and $\mathrm{F} 4$ were combined and re-run on a column. The column was similarly eluted and $20 \mathrm{ml}$ fractions were collected and monitored by tlc. On standing fractions $F^{\prime} 34, F^{\prime} 37, F^{\prime}$ 57, F'60 and $F^{\prime} 67$ yielded crystals that were further purified by recrystallization.

\section{RESULTS AND DISCUSSION}

Compound 1 was obtained as a white crystalline solid. The ${ }^{1} \mathrm{H}$ NMR spectrum of the compound revealed a multiplet at $\delta_{\mathrm{H}} 5.18$ typical of an olefinic H-5 or H-7 observed for steroids (Thuy et al., 2008). Two other signals for olefinic protons $\mathrm{H}-22$ and $\mathrm{H}-23$ were observed at $\delta_{\mathrm{H}} 5.35$ and 5.04. The proton spectrum also showed two methyl doublets at $\delta_{\mathrm{H}} 0.82,0.84(3 \mathrm{H}, \mathrm{d} J=6.5 \mathrm{~Hz})$ for an isopropyl unit in the steroid (Keawpradub et al., 2005). Two other methyl groups were observed at $\delta_{\mathrm{H}} 0.58$ and 1.02 and were assigned to the tertiary angular methyl groups at $\mathrm{C}-18$ and $\mathrm{C}-19$, while the two other methyl signals at $\delta_{\mathrm{H}} 1.03$ and 0.81 were for $\mathrm{C}-21$ and $\mathrm{C}-29$. The ${ }^{13} \mathrm{C}-\mathrm{NMR}$ spectrum confirmed the presence of a saturated ring ketone at $\delta_{\mathrm{C}} 212.07$ usually at C-3 of a steroid skeleton (Agrawal et al., 1985 and Ragas et al., 2014), three olefinic methine carbons were observed at $\delta_{c}$ 117.7 (C-7), 138.2 (C-22), 129.4 (C-23) and a quaternary olefinic carbon at $\delta_{\mathrm{C}} 139.5(\mathrm{C}-8)$. The ${ }^{13} \mathrm{C}$-NMR spectrum also showed six methyls, nine methylenes, ten methines and four aliphatic quaternary carbon signals. This further confirmed that compound $\mathbf{1}$ has a steroidal skeleton (Ragasa et al., 2014). Comparison of its chemical shift data (Table 1) with literature reports (Lee et al., 2011 and Ripardo Filho et al., 2012) identified the compound as spinasterone.

Compound 2 was obtained as a white powder. The ${ }^{1} \mathrm{H}$ and ${ }^{13} \mathrm{C}-\mathrm{NMR}$ spectra were similar to those of compound 1. However, the spectra of compound 2 also showed a typical pattern of a glucose moiety with the anomeric proton observed at $\delta_{\mathrm{H}} 4.41$ (Lee et al., 2013 and Benabdelaziz et al., 2014). The sugar was linked to C-3 of the aglycone as indicated by the higher chemical shifts for H-3 and C-3. Comparing the ${ }^{1} \mathrm{H}$ and ${ }^{13} \mathrm{C}$ NMR data for compound 2 (Table 1) and literature data, the compound was identified as daucosterol (Suga et al.,1999; Voutquenne et al., 1999 and Lee et al., 2011).

Compound 3 was also obtained as white crystals and had a melting point of $210-212{ }^{\circ} \mathrm{C}$. The compound gave a purple spot characteristic of a terpenoid on spraying with Vanillin-sulphuric acid reagent and heating. The ${ }^{1} \mathrm{H}$ NMR spectrum (Table 2) showed the presence of two methylene protons at ppm $4.69(\mathrm{~d}, J=1.68 \mathrm{~Hz})$ and $4.57 \mathrm{ppm}$, a methyl attached to a double bond at 1.69 and six other methyl groups between 0.77-1.04 ppm. Proton $\mathrm{H}-3$ and $\delta \mathrm{H}-19$ were observed at 3.19 (dd, $J=11.2,5.0 \mathrm{~Hz})$ and $2.38(\mathrm{ddd}, J=5.8,11.0,11.0$ $\mathrm{Hz}$ ) ppm respectively. The ${ }^{13} \mathrm{C}$ NMR from the Deptq-135 (Table 2) spectrum showed a total of 30 carbon atoms made up of seven methyl carbons, one oxygen bearing carbon, one methylene carbon and one quaternary carbon attached to the methylene group. No carbonyl carbon(s) were observed (confirmed by the absence of a carbonyl carbon in its ${ }^{13} \mathrm{C}$ NMR spectrum). The compound was identified as lupeol based on comparison to literature reports (Igoli and Gray,2008).

Compound 4 was obtained as a pale yellow powder (melting point $188-190^{\circ} \mathrm{C}$ ) and $\mathrm{Rf}=0.46$ on tlc with toluene/ethyl formate/formic acid (5:4:1:). Its UV $\max _{(\mathrm{CH} 3 \mathrm{CN})}(\mathrm{nm})$ maxima were observed at 205, 240, 292 and 318. The IR 
spectrum of the compound gave absorption bands at $3469(-\mathrm{OH}), 2933(\mathrm{C}-\mathrm{H}), 1686(\mathrm{C}=\mathrm{O}$ ester), 1642, 1513, 1542 (C=C), 1191 (C-O), 883 (Ar trisub) $\mathrm{cm}^{-1}$. The ${ }^{1} \mathrm{H}$ and ${ }^{13} \mathrm{C}-\mathrm{NMR}$ spectra showed aromatic and an alkanyl moiety. In the aromatic region, the proton spectrum showed an ABX spin system with signals at $\delta_{\mathrm{H}} 6.65(\mathrm{dd}, J=$ 8.2, $2.0 \mathrm{~Hz}), 6.59$ (d, J = 2.6 Hz), 6.51(m) respectively and are typical of a 1,3,4 trisubstituted phenyl unit and agrees with the IR spectrum (Fukuoka et al., 1982). Also, two pairs of doublets at $\delta_{\mathrm{H}} 7.34(\mathrm{~d}, J=15.8 \mathrm{~Hz})$ and $6.39(\mathrm{~d}, J=15.8 \mathrm{~Hz})$ were observed suggesting a trans propenyl chain. The ${ }^{1} \mathrm{H}$ and ${ }^{13} \mathrm{C}$ NMR indicated an oxygenated methylene group at $\delta_{\mathrm{H}} 4.16\left(\delta_{\mathrm{C}} 64.7\right)$, a methylene envelope between $\delta_{\mathrm{H}} 1.25-1.39\left(\delta_{\mathrm{C}} 23.1-32.4\right)$ for overlapping methylene signals $\left(28 \times \mathrm{CH}_{2}\right)$ and a terminal $\mathrm{CH}_{3}$ at $\delta_{\mathrm{H}} 0.90\left(\delta_{\mathrm{C}} 14.4\right)$ for the alkanyl moiety (Keawpradub et al., 2005). In the ${ }^{13} \mathrm{C}-\mathrm{NMR}$ spectrum a chemical shift at 167.3 confirmed the presence of an ester carbonyl group. The signals at 144.0 and 115.7 were for two olefinic carbons while the quaternary and phenolic carbons were observed at 146.1, 144.8, 122.7 and aromatic $-\mathrm{CH}$ at 116.5,115.7 and 122.0 all from a phenyl unit in the compound. The spectral data in comparison with literature reports confirmed compound 4 to be triacontanyl caffeate.

\section{Analytical Data for Triacontanyl Caffeate (4)}

White solid $\mathrm{mp}$ 188-190 ${ }^{\circ} \mathrm{C}$; TLC: $\mathrm{R}_{\mathrm{f}} 0.46$ (toluene/ethyl formate/formic acid (5:4:1); $\mathrm{UV}_{\text {max (CH3CN) }}(\mathrm{nm}) 205,240,292$ and 318; ESI-MS: $567.5[\mathrm{M}+\mathrm{Na}]^{+}$and $543.7[\mathrm{M}-\mathrm{H}]$; EI-MS m/z (rel. int.): 544 (3.5) [M] ${ }^{+}, 516$ (18), 459 (15), 446 (31),
180 (10), 125 (12), 111 (24), 97 (47), 69 (58), 43 (100); Exact Mass (HR EI-MS) m/z 544.4474 $\left[\mathrm{M}^{+}, \mathrm{C}_{35} \mathrm{H}_{60} \mathrm{O}_{4}\right.$ requires 544.4492; IR $v_{\max (\mathrm{KBr})}\left(\mathrm{cm}^{-1}\right)$ : $3469(-\mathrm{OH}), 2933(\mathrm{C}-\mathrm{H}), 1686$ (C=O ester), 1642 $(\mathrm{C}=\mathrm{C}), 1513,1542 \quad(\mathrm{C}=\mathrm{C}), 1191$ (C-O), 883 (Aromatic tri-subt.); ${ }^{1} \mathrm{H} \mathrm{NMR}\left(250 \mathrm{MHz}, \mathrm{CDCl}_{3}\right)$ (ppm): 0.89 (3H, t, J = $\left.7 \mathrm{~Hz},-\mathrm{CH}_{2}-\mathrm{Me}\right), 1.25$ (s, $\left.\left.\left[\mathrm{CH}_{2}\right]_{\mathrm{n}-2}\right]\right), 1.70\left(2 \mathrm{H}, \mathrm{m},-\mathrm{OCH}_{2}-\mathrm{CH}_{2}-\right), 5.42(1 \mathrm{H}, \mathrm{s},-$ $\mathrm{OH}), 5.54(1 \mathrm{H}, \mathrm{s},-\mathrm{OH}), 6.29(1 \mathrm{H}, \mathrm{d}, \mathrm{J}=15.87 \mathrm{~Hz}$, H-7), $6.88(1 \mathrm{H}, \mathrm{d}, \mathrm{J}=8.24 \mathrm{~Hz}, \mathrm{H}-6), 7.05(1 \mathrm{H}, \mathrm{dd}, \mathrm{J}$ $=8.55$ and $1.87 \mathrm{~Hz}, \mathrm{H}-5), 7.10(1 \mathrm{H}, \mathrm{d}, \mathrm{J}=1.87 \mathrm{~Hz}$, $\mathrm{H}-2)$ and $7.59(1 \mathrm{H}, \mathrm{d}, \mathrm{J}=15.87 \mathrm{~Hz}, \mathrm{H}-8) ;{ }^{13} \mathrm{C} \mathrm{NMR}$ $\left(250 \mathrm{MHz}, \mathrm{CDCl}_{3}\right)$ (ppm): 14.14 (C-35), 22.70 (C34), 26.01 (C-11), 28.77 (C-12), 29.32-29.72 (C13...C-32), 31.95 (C-33), 64.78 (C-10), 114.41 (C2), 115.56 (C-5), 116.08 (C-8) 122.43 (C-6), 127.85 (C-1), 143.76 (C-7), 144.48 (C-3), 146.09 (C-4), $167.62(\mathrm{C}-9)$.

Compound 5 was obtained from the column chromatography of the ethyl acetate extract on silica gel (eluted with 10\% ethyl acetate in hexane) as a pale yellow oil. The ${ }^{1} \mathrm{H}$ NMR showed two methyl singlets at $\delta_{\mathrm{H}} 2.09\left(\delta_{\mathrm{C}} 14.2\right)$ and $1.30\left(\delta_{\mathrm{C}}\right.$ 12.0). The spectral data obtained from its $2 \mathrm{D}$ NMR and literature reports identified the compound as linalonic acid (Omori et al., 2011). Analytical data for Linalonic acid.

${ }^{1} \mathrm{H} \mathrm{NMR}\left(500 \mathrm{MHz}, \mathrm{CDCl}_{3}, 1.39(3 \mathrm{H}, \mathrm{s}),, 1.63(1 \mathrm{H}\right.$, dddd, $J=19.8,16.5,8.0,4.2 \mathrm{~Hz}), 2.09(3 \mathrm{H}, \mathrm{s}), 2.28$ $(1 \mathrm{H}, \mathrm{m}), 2.76(1 \mathrm{H}, \mathrm{dd}, J=6.7,4.4 \mathrm{~Hz}), 3.73(1 \mathrm{H}, \mathrm{d}$, $J=4.9 \mathrm{~Hz}), 5.1(1 \mathrm{H}, \mathrm{d}, J=10.7), 5.23(1 \mathrm{H}, \mathrm{d}, J=$ $17.3 \mathrm{~Hz}), 5.90(1 \mathrm{H}, \mathrm{dd}, J=17.4,10.8 \mathrm{~Hz}), 6.87(1 \mathrm{H}$, $\mathrm{t}, J=7.5)$ 
<smiles>CC[C@H](/C=C/[C@@H](C)[C@H]1CC[C@H]2C3=CC[C@H]4CC(=O)CC[C@]4(C)[C@H]3CC[C@@]21C)C(C)C</smiles><smiles>C=CC(=O)CCC=C(C)C</smiles><smiles>CC[C@H](/C=C/[C@H](C)[C@H]1CC[C@]2(C)C3CC=C4C[C@@H](O[C@@H]5O[C@H](CO)[C@@H](O)[C@H](O)[C@H]5O)CC[C@]4(C)[C@]3(C)CC[C@]12C)C(C)C</smiles>

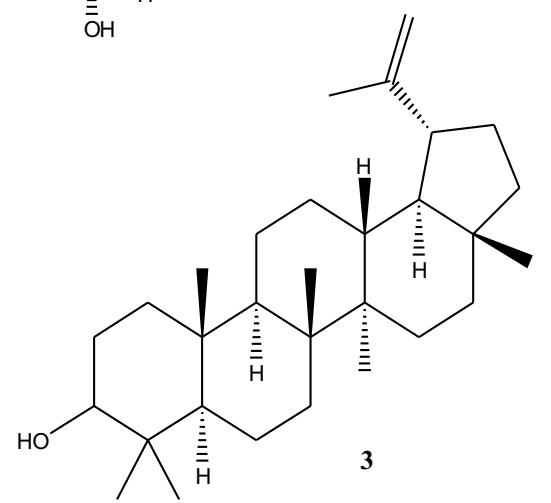<smiles>CCOC(=O)/C=C/c1ccc(O)c(O)c1</smiles> 
Nvau et al.: Isolation and Identification of Phytochemical Constituents

Table 1: ${ }^{1} \mathrm{H}$ and ${ }^{13} \mathrm{C}-\mathrm{NMR}$ data for compound 1 and 2

\begin{tabular}{|c|c|c|c|c|c|c|c|c|}
\hline \multirow{3}{*}{ Position } & \multicolumn{4}{|c|}{ Spinasterone } & \multicolumn{4}{|c|}{ Daucosterol } \\
\hline & \multicolumn{2}{|c|}{ Experimental } & \multicolumn{2}{|c|}{ Literature } & \multicolumn{2}{|c|}{ Experimental } & \multicolumn{2}{|c|}{ Literature } \\
\hline & $\begin{array}{c}\quad \delta_{\mathrm{H},} \\
\text { (mult.) }\end{array}$ & $\begin{array}{c}\delta_{\mathrm{C}} \\
(\mathrm{ppm})\end{array}$ & (mult.) & $\begin{array}{c}\delta_{C} \\
(\mathrm{ppm})\end{array}$ & $\begin{array}{l}\delta_{\mathrm{H}} \\
\text { (mult.) }\end{array}$ & $\begin{array}{c}\delta_{C} \\
(\mathrm{ppm})\end{array}$ & $\begin{array}{c}\delta_{\mathrm{H}} \\
\text { (mult.) }\end{array}$ & $\begin{array}{c}\delta_{\mathrm{C}} \\
(\mathrm{ppm})\end{array}$ \\
\hline 1 & $\begin{array}{l}1.48 \text { (td), } \\
2.13 \text { (ddd) }\end{array}$ & 38.9 & $\begin{array}{c}1.44(\mathrm{~m}), 2.13 \\
\text { (dddd) }\end{array}$ & 38.8 & $1.47,2.12$ & 38.9 & & 37.3 \\
\hline 2 & $2.26(\mathrm{~m})$ & 38.2 & 2.28 & 38.0 & 2.22 & 38.2 & & 29.4 \\
\hline 3 & - & 211.7 & - & 211.7 & -- & 79.2 & & 78.5 \\
\hline 4 & 2.26 & 44.4 & $2.24(\mathrm{~m})$ & 44.3 & 2.23 & 43.3 & & 38.4 \\
\hline 5 & 1.83 & 43.0 & $1.80(\mathrm{~m})$ & 42.3 & - & 139.5 & & 141.3 \\
\hline 6 & 1.83 & 30.2 & 1.83 & 42.9 & 5.18 & 117.7 & & 122.3 \\
\hline 7 & 5.18 & 117.2 & $5.18(\mathrm{~m})$ & 116.7 & 1.83 & 31.6 & & 31.8 \\
\hline 8 & - & 139.7 & - & 139.3 & 1.81 & 30.4 & & 30.6 \\
\hline 9 & 1.76 & 49.0 & $1.77(\mathrm{~m})$ & 48.9 & - & 49.1 & & 50.7 \\
\hline 10 & - & 34.6 & - & 34.4 & - & 37.0 & & 36.8 \\
\hline 11 & $1.55,1.76$ & 21.9 & $1.56,1.75$ & 21.7 & $1.56,1.75$ & 21.7 & & 20.4 \\
\hline 12 & $1.27,2.04$ & 39.5 & $1.27,2.04$ & 39.4 & $1.27,2.04$ & 40.2 & & 40.3 \\
\hline 13 & - & 43.4 & - & 43.4 & - & 41.7 & & 42.7 \\
\hline 14 & 1.76 & 55.2 & $1.83(\mathrm{~m})$ & 55.0 & 1.83 & 55.9 & & 56.9 \\
\hline 15 & $1.42,1.54$ & 23.2 & $1.39,1.50(\mathrm{~m})$ & 23.0 & $1.56,1.75$ & 23.9 & & 23.8 \\
\hline 16 & $1.27,1.68$ & 28.6 & $1.29,1.77$ & 28.6 & $1.29,1.67$ & 27.6 & & 26.7 \\
\hline 17 & 1.27 & 56.1 & 1.30 & 55.9 & 1.30 & 55.6 & & 56.6 \\
\hline 18 & 0.58 & 12.3 & $0.58 \mathrm{~s}$ & 12.0 & 0.68 & 12.3 & $0.67 \mathrm{~s}$ & 12.4 \\
\hline 19 & 1.02 & 12.6 & $1.02 \mathrm{~s}$ & 12.3 & 0.97 & 17.2 & $0.94 \mathrm{~s}$ & 19.6 \\
\hline 20 & 2.04 & 40.9 & $2.04(\mathrm{~m})$ & 40.9 & 2.05 & 34.6 & & 34.5 \\
\hline 21 & 1.03 & 21.8 & 1.02 & 21.8 & 1.03 & 20.4 & $1.00 \mathrm{~d}$ & 19.4 \\
\hline 22 & 5.35 & 138.2 & $5.13(\mathrm{dd})$ & 137.9 & 5.16 & 138.1 & & 32.6 \\
\hline 23 & 5.04 & 129.7 & $5.02(\mathrm{dd})$ & 129.4 & 5.02 & 129.3 & & 24.9 \\
\hline 24 & 1.54 & 51.4 & $1.55(\mathrm{~m})$ & 51.3 & 1.56 & 51.1 & & 46.4 \\
\hline 25 & $1.54(\mathrm{~m})$ & 32.1 & $1.56(\mathrm{~m})$ & 31.9 & 1.50 & 31.9 & & 28.9 \\
\hline 26 & $0.82(\mathrm{~d})$ & 19.1 & $0.82(\mathrm{~d})$ & 19.1 & 0.82 & 19.1 & 0.94 & 19.8 \\
\hline 27 & 0.81 & 20.5 & $0.84(\mathrm{~d})$ & 21.5 & 1.18 & 20.3 & 0.89 & 20.1 \\
\hline 28 & $\begin{array}{l}1.18(\mathrm{~m}) \\
1.42(\mathrm{~m})\end{array}$ & 25.4 & $\begin{array}{c}1.19(\mathrm{~m}), 1.41 \\
(\mathrm{~m})\end{array}$ & 25.5 & 1.12 & 21.4 & - & 21.7 \\
\hline 29 & 0.79 & 12.4 & $0.81(\mathrm{t})$ & 12.3 & 0.81 & 12.6 & 0.87 & 12.5 \\
\hline $1^{\prime}$ & & & & & $4.41(\mathrm{dd})$ & 101.1 & & 103.0 \\
\hline $2 '$ & & & & & 3.26 & 73.8 & & 75.8 \\
\hline $3^{\prime}$ & & & & & $3.44(t)$ & 76.7 & & 79.0 \\
\hline 4' & & & & & 3.42 & 70.5 & & 72.1 \\
\hline $5^{\prime}$ & & & & & 3.30 & 76.1 & & 78.9 \\
\hline $6^{\prime}$ & & & & & $4.51(\mathrm{dd})$ & 62.1 & & 63.2 \\
\hline
\end{tabular}


Table $2:{ }^{1} \mathrm{H}$ and ${ }^{13} \mathrm{CNMR}$ data for compound $\mathbf{3}$

\begin{tabular}{|c|c|c|c|c|}
\hline \multirow[t]{2}{*}{ Position } & \multicolumn{2}{|l|}{ Experimental } & \multicolumn{2}{|l|}{ Literature } \\
\hline & $\delta_{\text {н }}$ ppm (mult, J) & $\delta_{\mathrm{C}}(\mathrm{ppm})$ & $\delta_{\mathrm{H}}($ mult, $\mathrm{J})$ & $\delta \mathrm{C}(\mathrm{ppm})$ \\
\hline 1 & $0.96,1.61$ & 38.7 & $0.95,1.26$ & 38.7 \\
\hline 2 & 1.23 & 29.1 & 1.23 & 79.0 \\
\hline 3 & $3.12(\mathrm{dd}, J=11.4,5.03)$ & 79.0 & $3.16(\mathrm{dd}, J=11.2,5.2)$ & 79.0 \\
\hline 4 & - & 40.0 & - & 38.9 \\
\hline 5 & 0.69 & 55.3 & 0.65 & 55.3 \\
\hline 6 & $1.34,1.49$ & 18.3 & $1.33,1.48$ & 18.3 \\
\hline 7 & 1.37 & 34.3 & 1.36 & 34.3 \\
\hline 8 & - & 40.9 & - & 40.8 \\
\hline 9 & 1.23 & 50.5 & 1.23 & 50.4 \\
\hline 10 & - & 37.2 & - & 37.2 \\
\hline 11 & 1.34 & 20.9 & 1.33 & 21.0 \\
\hline 12 & 1.53 & 23.8 & 1.54 & 25.2 \\
\hline 13 & 1.59 & 38.1 & 1.59 & 38.1 \\
\hline 14 & - & 43.0 & - & 42.8 \\
\hline 15 & 1.49 & 27.4 & 1.49 & 27.5 \\
\hline 16 & $1.37,1.44$ & 35.6 & $1.36,1.44$ & 35.6 \\
\hline 17 & - & 42.9 & - & 42.0 \\
\hline 18 & 2.26 & 48.3 & 2.25 & 48.3 \\
\hline 19 & 1.29 & 48.0 & 1.28 & 48.0 \\
\hline 20 & - & 150.9 & - & 150.8 \\
\hline 21 & 1.23 & 30.4 & 1.23 & 29.9 \\
\hline 22 & $1.18,1.37$ & 40.9 & $1.18,1.36$ & 40.0 \\
\hline 23 & $0.93(\mathrm{~s})$ & 28.0 & $0.94(\mathrm{~s})$ & 28.0 \\
\hline 24 & $0.72(\mathrm{~s})$ & 14.1 & $0.73(\mathrm{~s})$ & 14.4 \\
\hline 25 & $0.84(\mathrm{~s})$ & 16.1 & $0.80(\mathrm{~s})$ & 16.2 \\
\hline 26 & $1.00(\mathrm{~s})$ & 16.3 & $1.00(\mathrm{~s})$ & 16.0 \\
\hline 27 & $0.92(\mathrm{~s})$ & 15.4 & $0.92(\mathrm{~s})$ & 14.6 \\
\hline 28 & $0.76(\mathrm{~s})$ & 18.0 & $0.76(\mathrm{~s})$ & 18.0 \\
\hline 29 & $4.50,4.62$ & 109.3 & $4.54,4.66$ & 109.2 \\
\hline 30 & $1.82(\mathrm{~s})$ & 19.3 & $1.65(\mathrm{~s})$ & 19.4 \\
\hline
\end{tabular}

\section{CONCLUSION}

The results obtained in the present investigation indicates that the roots of Calliandra portoricesis is rich in secondary metabolites. This is an initial isolation of linalonic acid, spinasterone, lupeol, daucosterol and triacontanyl caffeate from the plant material.

\section{REFERENCES}

Abdulkarim, A., Abdulrahman, E. M., Shok, M. and Sadiq, A.Y. (2005). Analgesic activities of the roots and leaves extract of Callindra portoricensis. Fitoterapia. 76: 442-445.

Adesina, S. K. (1982). Studies on some plants used as anticonvulsant in Amerindian and Africa traditional plant medicines. Fitoterapia. 53: 147-162

Aguwal, C. W. and Lawal, A. M. (1988). Pharmacological activities of the root and stem of Calliandra portoricensis. Journal of Ethnopharmacology. 20: 63-71

Akah, A. P. and Nwaiwu, I. J. (1988). Anticonvulsant activity of the root and stem of Calliandra portoricensis. Journal of Ethnopharmacology. 22: 205-210

Ayensu, E.S. (1978). Medicinal plants of West Africa. References publications Inc. Algonac Michigan, USA. 162-168

Benabdelaziz, B., Haba, H., Lavaud, C. and 
Benkhaled, M. (2014). Triterpenoids and flavonoid from Scorzonera undulata ssp. Alexandrina. IJCBS. 5:1-5.

Enwuru, V. N., Ogbonnia, S. O., Mbaka, G. O., J. E., Emordi, J. E., Ota, D. A. and Onyebuchi, P. (2017). Evaluation of Histomorphological, Toxicological and Antimicrobial Activities of Ethanolic Extract of Calliandra portoricensis Root in Rodents. Journal of Pharmacentical Research International. 18(5):1-13.

Falode, J. A., Obafemi, T. O., Akinmoladun, A. C., Olaleye, M. T., Boligon, A. A., Athayde, M. (2018). High-Performance Liquid Chromatography (HPLC) fingerprinting and comparative antioxidant properties of root bark and leaf extracts of Calliandra portoricensis. Archives. $1: 24-44$

Fukuoka, M. (1982). Chemical and toxicological studies on bracken fern, Pteridium aquilinum var. latiusculum. VI. Isolation of 5-O -caffeoylshikimic acid as an antithiamine factor. Chem. Pharm. Bull., 30: 3219-3224.

Hutchinson, J. M. (1937). Flora of West tropical Africa. Crown overseas Agent for the colonies. London, $2^{\text {nd }}$ ed. 227-238.

Igoli, J. O. and Gray, A. I. (2008). Friedelanone and other triterpenoids from Hymenocardia acida. International Journal of Physical Sciences. $3(6): 156-158$.

Keawpradub, N., Sukanya Dej-adisai, S. and Yuenyongsawad, S. (2005). Antioxidant and cytotoxic activities of Thai medicinal plants named Khaminkhruea: Arcangelisia flava, Coscinium blumeanum and Fibraurea tinctoria. Songklanakarin J. Sci. Technol.27:2:455-467

Lee, J. M., Lee, D. G., Ki, Ho Lee, K. H., Cho, S. H., Nam, K. W. and Lee, S. (2013). Isolation and identification of phytochemical constituents from the fruits of Acanthopanax senticosus. African Journal of Pharmacy and
Pharmacology.7 (6): 294-301.

Lee, S., Han, S., Kim, H. M., Lee, J. M., Mok, S. Y. and Lee, S. (2011). Isolation and identification of phytochemical constituents from Taraxacum coreanum. J. Korean Soc. Appl. Biol. Chem., 54:73-78.

Okoro, I. S., Tor, T. A., Anyiin, T., Igoli, J. O., Noundou, X. S and Krause, R.W.M. 2017. Isolation and Characterization of Stigmasterol and $\beta$-Sitosterol from Anthocleista djalonensis A. Chev. Asian Journal of Chemical Sciences. 3 (4):1-5.

Omori, H, Nakahara, K and Umano, K. 2011. Characterization of aroma compound in the peel extract of Jabar (Citrus jabara Hort. ex Tanaka). Flavour fragr, J. 26: 396402.

Ragasa, R., Galian, R. F., Arenal, M. Tan, V. and Shen, C. (2014). Triterpenes and sterols from Samanea saman. Research Journal of Pharmaceutical, Biological and Chemical Sciences. 5(4):1501-1507.

Ripardo Filho, H. S., Pacheco, L. C., Souza Filho, A. P. S., Guilhon, G.M.S.P., Arruda, M. S. P and Santos, L. S. (2012). Bioassays of Allelopathic Activity of the Steroids Spinasterol, Spinasterone, and Spinasterol Glucopyranosyl. Planta Daninha, ViçosaMG. 30 (4): 705-712.

Suga., Y. Takaishi., H. Nakagawa., T. Iwasa., M. S. and Okamoto, M. (2005). Chemical constituents from fruits and seeds of Myrica rubra (Myricaceae). Natural Medicines. 59 (2) 70-75.

Thuy, T. T., Sung, T. V., Frank, K. and Wesjohann, L. (2008). Triterpenes from the roots of Codonopsis pilosula. Journal of Chemistry. 46 (4) : 515-520.

Voutquenne, L., C. Lavaud, C., Massiot, G., Sevenet, T., and Hadi, H. A. (1999). Cytotoxic polyisoprenes and glycosides of long-chain fatty alcohols from Dimocarpus fumatus. Phytochemistry. 50 (1): 63-69. 